NOTE

\title{
Effects of shoot stiffness, shoot size and current velocity on scouring sediment from around seedlings and propagules
}

\author{
T. J. Bouma ${ }^{1, *}$, M. Friedrichs ${ }^{2}$, P. Klaassen ${ }^{1}$, B. K. van Wesenbeeck ${ }^{1,3}$, F. G. Brun ${ }^{1}$, \\ S. Temmerman ${ }^{4}$, M. M. van Katwijk ${ }^{5}$, G. Graf ${ }^{2}$, P. M. J. Herman ${ }^{1}$ \\ ${ }^{1}$ Centre for Estuarine and Marine Ecology, Netherlands Institute of Ecology (NIOO-KNAW), PO Box 140, \\ 4400 AC Yerseke, The Netherlands \\ ${ }^{2}$ Institute for Biological Sciences-Marine Biology, University of Rostock, Albert-Einstein-Str. 3, 18051 Rostock, Germany \\ ${ }^{3}$ Deltares, Marine and Coastal Systems, PO Box 177, 2600 MH Delft, The Netherlands \\ ${ }^{4}$ Department of Biology, University of Antwerp, Universiteitsplein 1, 2610 Wilrijk, Belgium \\ ${ }^{5}$ Department of Environmental Science, Radboud University Nijmegen, PO Box 9010, 6500 GL Nijmegen, The Netherlands
}

\begin{abstract}
Successful management and restoration of coastal vegetation requires a quantitative process-based understanding of thresholds hampering (re-)establishment of pioneer vegetation. We expected scouring to be important in explaining the disappearance of seedlings and/or small propagules of intertidal plant species, and therefore quantified the dependence of scouring on plant traits (flexibility, size) and physical forcing by current velocity. Flume studies with unidirectional flow revealed that scouring around seedlings increased exponentially with current velocity and according to a power relationship with plant size. Basal stem diameter rather than shoot length controlled scouring volume. Flexible shoots caused far less scouring than stiff shoots, provided that the bending occurred near the sediment surface as was the case for Zostera, and not on top of a solid tussock base as we observed for Puccinellia. Therefore, shoot stiffness is likely to strongly affect the chances for initial establishment in hydrodynamically exposed areas. Plant traits such as shoot stiffness are subject to a trade-off between advantages and disadvantages, the outcome of which depends on the physical settings.
\end{abstract}

KEY WORDS: Seedling survival $\cdot$ Hydrodynamics $\cdot$ Current velocity $\cdot$ Spartina anglica $\cdot$ Salt marsh $\cdot$ Trade-offs $\cdot$ Seagrass $\cdot$ Zostera noltii

\section{INTRODUCTION}

Coastal vegetation is regarded as a highly valuable ecosystem in that it provides a broad range of ecosystem services, but is threatened world-wide by global change processes and anthropogenic disturbances (Lotze et al. 2006, Orth et al. 2006, Barbier et al. 2008). Large areas of coastal vegetation are frequently lost while (re-)establishment of vegetation on bare sediment appears to have low chances of success (e.g. see van Wesenbeeck 2007, van Katwijk et al. 2009 and references therein). A meta-analysis of seed addition ex- periments (Clark et al. 2007) suggested that establishment limitations are generally stronger than seed limitations (for salt marshes see Rand 2000, Garbutt et al. 2006), meaning that understanding the re-establishment of coastal vegetation on natural bare mudflats requires insight into the processes that cause seedling and/or propagule loss. Recent studies have suggested that coastal vegetation such as seagrasses and pioneer saltmarsh vegetation may follow the alternative stable states theory (van der Heide et al. 2007, van Wesenbeeck 2007), indicating that positive feedback loops influence their dynamics and that minimum thresholds 
need to be surpassed for state changes to occur (e.g. see Scheffer et al. 2001 and references therein). Transplantation experiments with seagrass and salt-marsh plants revealed that surpassing biomass or density thresholds may increase seedling survival of intertidal vegetation significantly (Bos \& van Katwijk 2007, van Wesenbeeck 2007). Here we attempted to obtain a quantitative understanding of the processes inducing thresholds for seedling and/or propagule settlement, as this is highly important for coastal management and restoration.

At low intertidal elevations, hydrodynamic forces from waves and currents are known stress factors that influence settlement and survival of many intertidal species (e.g. see Bruno 2000, Robbins \& Bell 2000, Bos \& van Katwijk 2007). This applies to a broad range of different vegetation types, including intertidal seagrass vegetation with flexible shoots as well as saltmarsh vegetation that can have stiff shoots or flexible shoots on a solid tussock base. In riparian vegetation along rivers, scouring by high flows has been identified as one of the main reasons for seedling mortality (Polzin \& Rood 2006). As scouring by high velocities can negatively affect the lateral expansion of tussocks in intertidal systems (van Wesenbeeck et al. 2008 and references therein), scouring may also be an important factor in explaining the disappearance of seedlings and/or propagules of intertidal plant species. Previous studies have shown that shoot stiffness is a major influence for the drag forces on individual shoots and for the way in which shoots modify local hydrodynamics and thereby sediment dynamics (Bouma et al. 2005). Shoot stiffness may therefore also determine scouring around propagules, which in turn may be decisive for survival and establishment of new vegetation.

In order to develop a mechanistic understanding of the processes that may affect recruitment in salt-marsh and seagrass ecosystems and to further enhance our fundamental understanding of the role of shoot stiffness for the functioning of vegetation in hydrodynamically driven ecosystems, we quantified scouring processes in relation to the flexibility and size of plants and to physical forcing by current velocity. We addressed these questions in a flume study by analysing how seedlings of different size for species with contrasting stiffness, as well as defined mimics with similar shape but different mechanical properties, affect overall scouring volumes.

\section{MATERIALS AND METHODS}

Mimics of individual single plant shoots were used to measure how the combination of stiffness, diameter and shoot length affects scouring. Whereas in natural species such traits are often correlated, using mimics allowed us to vary these plant traits independently. We used strips of contrasting flexibilities to determine the effect of shoot stiffness. Zostera-like flexible plant mimics were made by cutting a plastic folder into strips (100 mm long, $5 \mathrm{~mm}$ wide) and tie-wraps (cable ties) of identical dimensions were used to mimic stiff Spartina shoots (cf. Bouma et al. 2005). The single strips to mimic a single shoot were placed with the $5 \mathrm{~mm}$ wide area facing the current. To quantify the effect of stem diameter and stem length on scouring, single metal bars were used to mimic differences in stem diameter and stem length.

In addition to plant mimics, we also studied real plants of Spartina anglica, Zostera noltii and Puccinellia maritima. The stiff salt-marsh pioneer Spartina and the flexible seagrass $Z$. noltii inhabit the lower parts of the vegetated intertidal marsh areas in most of NW Europe (Bouma et al. 2005), whereas the flexible marsh species Puccinellia dominates pioneer zones in the barrier islands in the Dutch Wadden Sea (Bakker et al. 2002). The flexible Puccinellia grows as small above-ground tussocks with a massive base, whereas Spartina and Zostera have below-ground rhizomes so that the above-ground plants appear to exist of individual shoots. Individual Spartina and Puccinellia plants were cultured from seed in a growth chamber, in trays that exactly fitted the test section of the re-circulating Rostock laboratory flume $(1 \mathrm{~m} \times 0.25 \mathrm{~m}$ and $0.1 \mathrm{~m}$ deep); $Z$. noltii was transplanted from the field.

Sediment dynamics (median grain size of $192 \pm$ $1.9 \mu \mathrm{m} ; \mathrm{n}=8$ ) around plants and mimics were measured at Rostock University in a re-circulating laboratory flume channel with a $3 \mathrm{~m}$ long and $0.4 \mathrm{~m}$ wide channel. For a full explanation of the technical aspects of the flume and its instrumentation and the rationale behind the hydrodynamic settings, we refer to Bouma et al. (2009) and references therein. Here we briefly summarise the most important points. Current was generated by a propeller in the return pipe and turbulence levels in the flume were reduced by collimator grids in the inflow zone. Current velocity was measured with an acoustic Doppler flow sensor (ADV) at $5 \mathrm{~cm}$ above the bottom and was around $0.35 \mathrm{~m} \mathrm{~s}^{-1}$ at a water level of $0.12 \mathrm{~m}$. These flow conditions are representative for the early phase of the upcoming flood in the estuarine systems that we study. After 30 min of exposure to a flow of $0.35 \mathrm{~m} \mathrm{~s}^{-1}$, the sediment dynamics had reached steady state, meaning that longer time does not cause additional scouring. Plants were cut off at the sediment surface, whereafter changes in surface elevation were measured using an automated laser system mounted to a 3D-positioning carriage. This laser system offered a vertical detection accuracy of $0.3 \mathrm{~mm}$, while using a spatial grid resolution of $3 \mathrm{~mm}$ in both the $\mathrm{X}$ (parallel to the flow) and the Y (cross-stream) direction. 


\section{RESULTS}

Exposure to current velocity caused clear scouring patterns around seedlings and plant mimics. The eroded volume increased exponentially with current velocity, which was more pronounced for stiff than for flexible structures (Fig. 1). Measurements on single shoots of Spartina and Zostera noltii confirmed the difference that was observed between the stiff and flexible mimic strips (Fig. 1). In contrast to this, the eroded

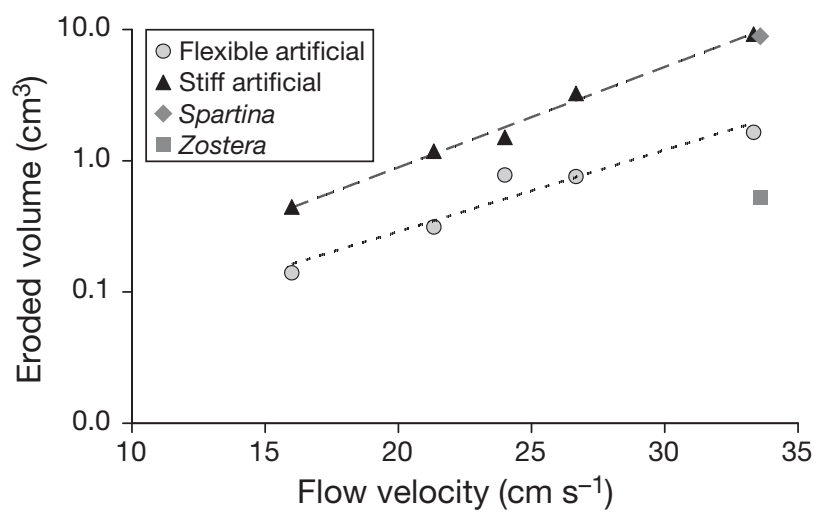

Fig. 1. Effect of shoot stiffness and current velocity on scouring volume, as assessed by comparing mimics with exactly the same dimensions (100 mm long, $5 \mathrm{~mm}$ wide) but differing in stiffness. The Zostera-like flexible plant mimics consisted of a single thin plastic strip, whereas the Spartina-like stiff plant mimics consisted of a single tie-wrap (cable tie; cf. Bouma et al. 2005). Each point represents a single measurement. For the highest velocity, the results of the mimics were compared to single measurements on seedlings of $S$. anglica and $Z$. noltii. Regression lines for Spartina-like stiff mimics and Zostera-like flexible mimics are, respectively, as follows: eroded volume $=0.0262 \mathrm{e}^{0.176 \times \text { veloc }}\left(\mathrm{R}^{2}=0.99\right)$ and eroded volume $=0.0165 \mathrm{e}^{0.143 \times \text { veloc }}\left(\mathrm{R}^{2}=0.94\right)$

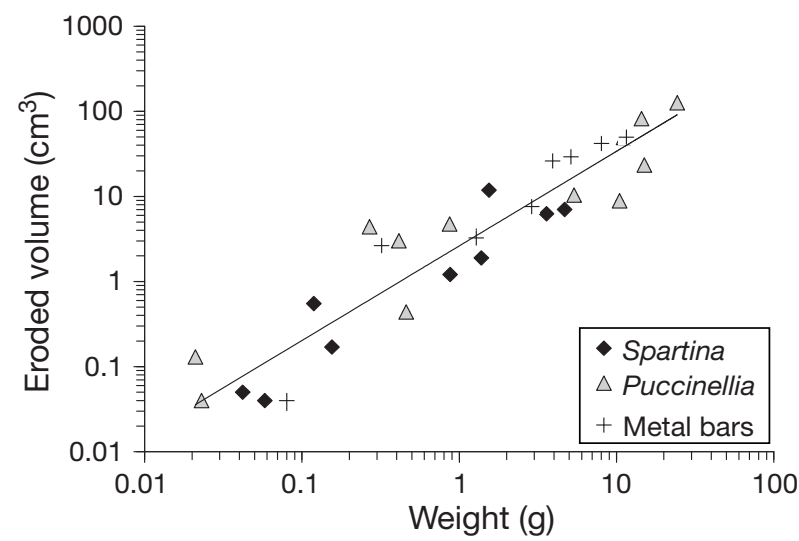

volume did not differ between stiff Spartina, flexible Puccinellia and metal bars over a range of sizes (Fig. 2). These measurements only showed that the eroded volume strongly increased with plant size expressed either by weight (for metal bars, 'weight' was recalculated using the observed weight:volume ratio of plants) or cumulative stem diameter and was independent of shoot stiffness (Fig. 2). We observed that the Puccinellia seedlings rapidly formed a solid tussock base that formed a visible obstruction to the flow, whereas the flexibility is only present higher up in the water column (data not shown). To test if this might explain the contrasting observations on the scouring effect of flexible vegetation, we compared scouring around metal bars of different length and diameter. These tests showed that the eroded volume was mainly determined by the basal diameter. Reducing the length of a bar had no effect on the eroded volume, even though the overall volume of the bar was strongly reduced (Fig. 3). Thus, the solid tussock base of Puccinellia drives scouring, whereas the flexibility higher up in the water column has no influence on the scouring. Overall, these results show that both stiff plants and flexible plants with a solid tussock base cause significant scouring (Fig. 2), whereas scouring around seagrass-like plants with flexible bases is minimal (Fig. 1), and that plant diameter rather than shoot length determines the degree of scouring (Fig. 3).

\section{DISCUSSION}

Since scouring is known to cause seedling mortality in riparian vegetation (Polzin \& Rood 2006), there is urgent need for mechanistic insight in scouring around

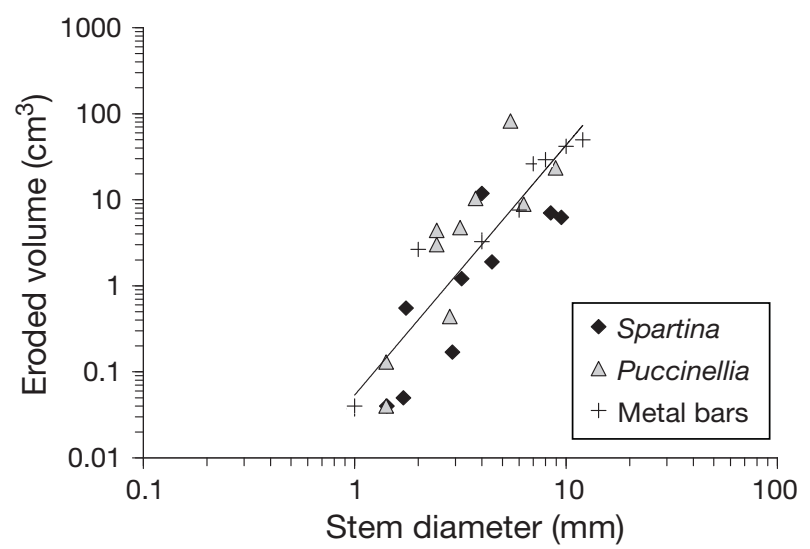

Fig. 2. Effect of shoot size expressed as fresh weight (FW, left) or overall stem diameter (right) on scouring volume, comparing the stiff salt marsh pioneer Spartina anglica, the flexible marsh species Puccinellia maritima and single metal bars. The plant FW includes the total of the aboveground materials. The weight of the metal bars was calculated by multiplying the volume of the bar with a weight:volume ratio of $0.86 \pm 0.1 \mathrm{~g} \mathrm{FW} \mathrm{cm}^{-3}$ as determined for Spartina and Puccinellia plants $(\mathrm{n}=8)$. For Spartina, we used the diameter of the mature main shoot. If there were 2 mature shoots causing erosion, the sum of both diameters was taken. For Puccinellia, the diameter reflects the diameter of the tussock base. Regression lines are as follows: eroded volume $=2.63 \times$ weight $^{1.11}\left(\mathrm{R}^{2}=0.87\right)$ and eroded volume $=0.05 \times(\text { stem diameter })^{2.90}\left(\mathrm{R}^{2}=0.77\right)$ 


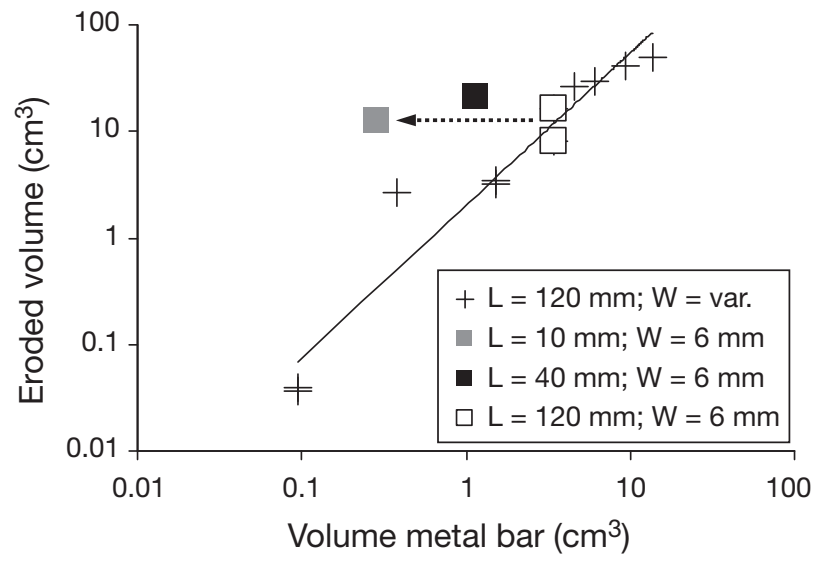

Fig. 3. Visual demonstration of the importance of the basal bar diameter (W) rather than bar volume in determining scouring volume. A reduction of bar volume by reducing the length (L) does not affect the scouring volume (shift along arrow). Regression line for all metal bars of $120 \mathrm{~mm}$ length is as follows: eroded volume $=2.04 \times(\text { volume bar })^{1.43}\left(\mathrm{R}^{2}=0.94\right)$

seedlings and/or propagules of world-wide declining seagrasses and intertidal salt-marsh species. Our flume study revealed that scouring around seedlings strongly increases with current velocity, basal diameter and shoot stiffness, provided that the bending occurred near the sediment surface and not on top of a solid tussock base. We note, however, that while our flume study illustrates general principles on the relation between scouring and plant traits (Figs. 1 to 3), quantitative predictions for different locations will depend on local hydrodynamics and sediment properties.

Large-scale observations on extension of coastal vegetation in relation to shelter (Fonseca \& Bell 1998, van der Wal et al. 2008 and references therein) support the contention that physical factors are of overruling importance in seedling and/or propagule survival for both stiff and flexible species. Knowledge on the critical erosion levels causing seedling/propagule mortality remains scarce, but indicates that a $2 \mathrm{~cm}$ erosion may cause $50 \%$ mortality in some species (Houwing 2000, Cabaço et al. 2008). Hence we postulate that in the case of stiff seedlings or propagules (including flexible seedlings with stiff bases), seedling and/or propagule survival could be related to scouring processes, whereas in flexible plants, this might only be the case under extreme hydrodynamic conditions. The evident importance of plant flexibility/stiffness in combination with plant morphology (i.e. forming a dense tussock or not) on scouring is likely to have consequences for the chances of seedling or propagule establishment of different plant species in hydrodynamically exposed areas. A high flexibility as e.g. in the seagrass Zostera noltii is likely to offer a higher chance for establishment in relatively exposed tidal flats (cf. van Katwijk \& Wijgergangs 2004) than the stiff shoot morphology of the marsh species Spartina and the dense tussock formation of Puccinellia.

Despite the clear influence of shoot stiffness on the chances for initial establishment, it is not possible to directly extrapolate this to fitness consequences. For example, hydrodynamic forces may prevent established seagrass seedlings from developing into adult plants (van Katwijk \& Wijgergangs 2004), suggesting that flexible tissues may be too weak to tolerate the mechanical stress. On the other hand, flexibility may be highly important in preventing desiccation stress to seagrasses that live in intertidal zones, by keeping plants moist during low tide by lying flat on the wet sediments (Boese et al. 2005). The stiff stems that may initially hamper the establishment of Spartina seedlings may later have a strong positive effect on plant performance by trapping sediment and particulate materials (van Wesenbeeck et al. 2008).

In summary, our study on scouring around seedlings provides additional evidence that shoot stiffness reflects clear trade-offs to plants living in intertidal ecosystems (Bouma et al. 2005), with the costs and benefits involving a broad range of factors that deserve more study. Whereas it is clear that scouring around seedlings strongly increases with current velocity, basal diameter and shoot stiffness, a better insight into the role of erosion for seedling and/or propagule survival requires further investigation.

Acknowledgements. We thank B. Koutstaal, J. van Soelen and $\mathrm{H}$. Pielenz for their technical support. Travelling was funded by the Schure-Beijerinck-Popping fund (SBP/JK/ 2004-25 \& SBP/JK/2005-38). F.G.B. was supported by an individual Marie Curie fellowship (EU contract MEIF-CT-2005515071) and by a European Reintegration Grant (EU contract MERG-CT-2007-205675). We acknowledge STW-NWO grant 07324 for funding our research to the application of salt marsh in coastal defence.

\section{LITERATURE CITED}

Bakker JP, Esselink P, Dijkema KS, van Duin WE, de Jong DJ (2002) Restoration of salt marshes in the Netherlands. Hydrobiologia 478:29-51

- Barbier EB, Koch EW, Silliman BR, Hacker SD and others (2008) Coastal ecosystem-based management with nonlinear ecological functions and values. Science 319: 321-323

Boese BL, Robbins BD, Thursby G (2005) Desiccation is a limiting factor for eelgrass (Zostera marina L.) distribution in the intertidal zone of a northeastern Pacific (USA) estuary. Bot Mar 48:274-283

Bos AR, van Katwijk MM (2007) Planting density, hydrodynamic exposure and mussel beds affect survival of transplanted intertidal eelgrass. Mar Ecol Prog Ser 336: 121-129

Bouma TJ, De Vries MB, Low E, Peralta G, Tánczos IC, van de 
Koppel J, Herman PMJ (2005) Trade-offs related to ecosystem-engineering: a case study on stiffness of emerging macrophytes. Ecology 86:2187-2199

Bouma TJ, Friedrichs M, van Wesenbeeck BK, Temmerman S, Graf G, Herman PMJ (2009) Density-dependent linkage of scale-dependent feedbacks: a flume study on the intertidal macrophyte Spartina anglica. Oikos 118:260-268

Bruno JF (2000) Facilitation of cobble beach plant communities through habitat modification by Spartina alterniflora. Ecology 81:1179-1192

Cabaço S, Santos R, Duarte CM (2008) The impact of sediment burial and erosion on seagrasses: a review. Estuar Coast Shelf Sci 79:354-366

Clark CJ, Poulsen JR, Levey DJ, Osenberg CW (2007) Are plant populations seed limited? A critique and metaanalysis of seed addition experiments. Am Nat 170: 128-142

Fonseca MS, Bell SS (1998) Influence of physical setting on seagrass landscapes near Beaufort, North Carolina, USA. Mar Ecol Prog Ser 171:109-121

Garbutt RA, Reading CJ, Wolters M, Gray AJ, Rothery P (2006) Monitoring the development of intertidal habitats on former agricultural land after the managed realignment of coastal defences at Tollesbury, Essex, UK. Mar Pollut Bull 53:155-164

Houwing EJ (2000) Morphodynamic development of intertidal mudflats: consequences for the extension of the pioneer zone. Cont Shelf Res 20:1735-1748

Lotze HK, Lenihan HS, Bourque BJ, Bradbury RH and others (2006) Depletion, degradation, and recovery potential of estuaries and coastal seas. Science 312:1806-1809

- Orth RJ, Carruthers TJB, Dennison WC, Duarte CM and others (2006) A global crisis for seagrass ecosystems. BioScience 56:987-996

Editorial responsibility: Morten Pedersen,

Roskilde, Denmark
Polzin ML, Rood SB (2006) Effective disturbance: seedling safe sites and patch recruitment of riparian cottonwoods after a major flood of a mountain river. Wetlands 26:965-980

Rand TA (2000) Seed dispersal, habitat suitability and the distribution of halophytes across a salt marsh tidal gradient. J Ecol 88:608-621

Robbins BD, Bell SS (2000) Dynamics of a subtidal seagrass landscape: seasonal and annual change in relation to water depth. Ecology 81:1193-1205

Scheffer M, Carpenter S, Foley JA, Folke C, Walker B (2001) Catastrophic shifts in ecosystems. Nature 413:591-596

van der Heide T, van Nes EH, Geerling GW, Smolders AJP, Bouma TJ, van Katwijk MM (2007) Positive feedbacks in seagrass ecosystems - theoretical and management implications. Ecosystems 10:1311-1322

> van der Wal D, Wielemaker-Van den Dool A, Herman PMJ (2008) Spatial patterns, rates and mechanisms of saltmarsh cycles (Westerschelde, The Netherlands). Estuar Coast Shelf Sci 76:357-368

> van Katwijk MM, Wijgergangs LJM (2004) Effects of locally varying exposure, sediment type and low-tide water cover on Zostera marina recruitment from seed. Aquat Bot 80: $1-12$

van Katwijk MM, Bos AR, de Jonge VN, Hanssen LSAM, Hermus DCR, de Jong DJ (2009) Guidelines for seagrass restoration: importance of habitat selection and donor population, spreading of risks, and ecosystem engineering effects. Mar Pollut Bull 58:179-188

van Wesenbeeck BK (2007) Thresholds and shifts: consequences of habitat modification in salt-marsh pioneer zones. PhD thesis, University of Groningen

van Wesenbeeck BK, van de Koppel J, Herman PMJ, Bouma TJ (2008) Does scale-dependent feedback explain spatial complexity in salt-marsh ecosystems? Oikos 117:152-159

Submitted: May 20, 2008; Accepted: May 26, 2009

Proofs received from author(s): July 27, 2009 